\title{
Image that Matters: News Media Consumption and Party Leader Effects on Voting Behavior
}

The International Journal of Press/Politics 2020, Vol. 25(2) 238-259

(C) The Author(s) 2019

Article reuse guidelines: sagepub.com/journals-permissions DOI: $10.1177 / 1940161219894979$ journals.sagepub.com/home/hij

(S)AGE

\section{Diego Garzia' (iD), Frederico Ferreira da Silva², and Andrea De Angelis'}

\begin{abstract}
Television is customarily put forward as a driver of the "personalization of politics." The characteristics of this visual medium arguably accentuate personality at the expense of substantive programmatic goals, downplaying partisan attachments and ideology as determinants of the vote in favor of candidate and party leader assessments. While there is evidence of this trend for presidential democracies, notably the United States, this linkage is yet to be fully explored for parliamentary democracies undergoing a process of personalization. This study addresses this gap through an analysis of pooled national election study data from thirteen Western European parliamentary democracies collected between 1982 and 2016 . Our results show that leader effects are significantly stronger among individuals with a televisiondominant media diet. The findings provide support to the yet underdeveloped theoretical relationship between media change and the personalization of politics, while also speaking to the broader question involving the importance of media for contemporary democratic elections.
\end{abstract}

\section{Keywords}

personalization of politics, newspapers, television, voting behavior

\footnotetext{
University of Lucerne, Lucerne, Switzerland

${ }^{2}$ European University Institute, Fiesole, Italy

\section{Corresponding Author:}

Diego Garzia, Department of Political Science, University of Lucerne, Frohburgstrasse 3, 6002 Lucerne, Switzerland.

Email: diego.garzia@unilu.ch
} 


\section{Introduction}

Over the last two decades, the personalization of politics has attracted increasing interest among social and political scientists, particularly concerning its electoral face, that is, the impact of voters' assessments of individual politicians on their voting decisions (Garzia 2017a, 2014; Holmberg and Oscarsson 2011; Karvonen 2010). Rahat and Kenig (2018: 121) argue that political personalization "implies a change in behaviours such as voting, which tends to follow the evaluations of leaders . . . and is done less and less according to party loyalty, identity and ideology." In this respect, the literature distinguishes two main processes at the origin of leaders' growing electoral preponderance. On one hand, the weakening of long-term affective attachments to political parties, as a result of the erosion of partisan alignments over the latest decades of the twentieth century, has downplayed the importance of parties vis-à-vis leaders and leading candidates in the voting calculus (Dalton et al. 2000). The resulting transformations in structure and organization undergone by political parties have also contributed to further heightening the role of party leaders (Mair et al. 2004). On the other hand, a parallel process of media change has brought about transformations in political communication as well as on voters' patterns of consumption of political information (Altheide and Snow 1979; Mazzoleni 1987). Television has revolutionized the shape of political messages, tailored to suit the rapidly wide-spreading new media. This image-based medium disfavors a type of communication built on complex programmatic contents or abstract ideologies. Rather, television cultivates a personalized form of communication, grounded on the visible faces of political parties, that is, their leaders and leading candidates (Mazzoleni 2000).

Political communication research has for long maintained that television has been decisive in increasing the electoral role of individual politicians at the expense of partisan attachments or ideology (Aaldering 2018; Lenz and Lawson 2011). When it comes to the political behavior literature, however, the available empirical studies provide only mixed evidence. While some studies confirm the relationship between exposure to televised political information and increased leader effects (Garzia 2017b; Holian and Prysby 2014; Keeter 1987; McLeod et al. 1983; Mughan 2000; Takens et al. 2015), others find only partial or no evidence of a correlation between consumption of televised news and leader-centered patterns of voting behavior (ElmelundPræstekær and Hopmann 2012; Gidengil 2011; Hayes 2009; Rico 2014). In this article, we argue that these discrepancies are primarily attributable to methodological shortcomings of three different types. First, virtually all existing studies are cross-sectional and/or single-country cases. Second, even among the few comparative analyses, measurement issues subsist due to their focus on exposure to the medium in general rather than exposure to political news. Third, none of the existing studies considers the composition of individuals' media diet, that is, the extent to which their political information consumption habits are diversified across different types of media.

This article attempts at tackling these limitations seeking to provide evidence of the relationship between exposure to political information through different media (newspapers and television) and the importance of leaders for vote choice. ${ }^{1}$ In particular, we 
hypothesize that a television-dominated media diet primes leader effects on vote choice, whereas a newspaper-dominated media diet hinders them. We offer an extensive empirical assessment of this hypothesis based on an original pooled data set featuring forty-eight national election studies conducted in thirteen West European parliamentary democracies between 1982 and 2016.

\section{Television and the Personalization of Politics}

The later decades of the twentieth century were marked by the first symptoms of party decline in western democracies (Dalton et al. 2011). The decrease in the levels of turnout, party identification, and party membership are all illustrative of the fact that "parties are no longer managing to engage the ordinary citizen" (Mair 2006: 32). Cognitive mobilization and broader social structure reconfigurations transformed electoral markets by eroding traditional cleavages and weakening party attachments, leading to a crisis of political parties (Mair et al. 2004). As group-based identifications forging the attitudinal attachments to political parties lose much of their importance, voting becomes, essentially, an individual enterprise. Electoral volatility increases as voters no longer continuously pledge allegiance to a single political party (Dalton et al. 2000). An increasingly complex electorate, unconstrained by partisan bonds, thus came to consider a multitude of factors in their voting decisions, among which candidate and party leader evaluations stand out as an increasingly relevant factor in a context of political personalization.

The changing structure of mass communication is widely assumed to have played a role in the development of personalized voting behavior patterns (Lenz and Lawson 2011). The combination of audio and visual elements inherent to televised communication went beyond a mere technological transformation, to entail "the greatest anthropological revolution of all times" (Sartori 1989: 43). The visual possibilities of television gave individuals the option not only to read about what happened but also to watch. In turn, this transformed the notion of objectivity - it is no longer enough to read about it, one must see it - and conferred additional trustworthiness to televised news (Postman 1986).

The fact that television primes images rather than written content, and that it is directed at entertainment rather than abstract reflection, imposes substantial constraints on the type of political messages to be conveyed. Unlike the written format, this setting is not ideal for communicating complex ideas, programmatic goals, ideologies, or political issues. By prioritizing personality rather than abstract contents, television favors superficial coverage, communication through visual objects instead of abstract concepts, and appeals to emotions even through non-verbal communication (Hayes 2009; Langer 2010). In doing so, television not only altered parties' political communication strategies, forcing them to adapt. It also transformed voters' patterns of consumption of political information, reinforcing the demand for more personalized political competition (Prior 2006).

The changing structure of mass communications in the second half of the twentieth century has been central in emphasizing the role of political leaders at the expense of 
parties, making the latter "more dependent in their communications with voters on the essentially visual and personality-based medium of television" (Mughan 2000: 129). It thus became crucial for political parties to convey their message through visual images and personalities,

ensuring that their leaders had, for the most part, the visual appeal and communication skills that suited the new medium. When a new party leader is chosen, it is taken for granted that one of the main selection criteria is how they present themselves on television. (Dalton et al. 2011: 219)

Based on a review of preexisting theoretical accounts, we foresee two possible mechanisms behind differentiated patterns of media exposure and leader effects. On one hand, it is argued that television coverage is inherently more personalized (Elmelund-Præstekær and Hopmann 2012). Televised political news are increasingly privatized around individual political actors (Rahat and Sheafer 2007; van Aelst et al. 2011), in a process reinforced by politicians' and parties' increasing highlight on personality (Sheafer 2001; Strömback 2008). ${ }^{2}$ On these basis, leaders are supposed to matter because of their strictly personal characteristics (as conveyed by privatized political news in television). On the other hand, it has been hypothesized that the difference between mediums may depend almost exclusively on the nature of the information delivered. As television conveys more visual images and non-verbal cues, this may lead voters to more heavily rely on this additional information for their electoral decisions. The latter mechanism is well exemplified in Druckman's (2003) experiment. Reproducing the 1960 Kennedy-Nixon debate for two distinct groups of subjects (via television vs. via radio), under the hypothesis that television watchers would consider additional non-verbal information provided by visual imagery or cues based on movements and appearances used every day in subjects' daily relationships, he found significant differences between the two groups. Television watchers considered Kennedy to have won the debate, while radio listeners found Nixon's performance better - the reason being advanced that television favored Kennedy's superior image even though he was not necessarily better on issues (Druckman 2003). Similar conclusions were reached by Mendelsohn (1996), who found that leader effects are trumping issue voting and partisanship's effect because of the media's role in priming candidates. Lenz and Lawson (2011) found parallel results for U.S. Senate and House elections: appealing-looking candidates are especially benefited from television exposure, in particular among less sophisticated citizens who watch a substantial amount of television. A similar pattern of image-based voting had been previously identified by Todorov et al. (2005), who demonstrate that voters' inferences of competence relying exclusively on facial appearance were a strong predictor of the outcomes of U.S. congressional elections.

Importantly, both mechanisms imply that a higher degree of television exposure should correspond to a greater consideration of candidate assessments on vote choice vis-à-vis partisanship and ideological considerations. On the contrary, voters more exposed to political information on newspapers, being exposed to textual information 
with a lower degree of personalization, should rely less heavily on candidate evaluations in their voting decision making. Naturally, there should be a positive relationship between the frequency of consumption of political information on each of these mediums and the influence they bear on the vote. However, mere quantity of exposure should not be determinant. The potential heterogeneity of voters' media sources and their relative weight on the composition of individual media diets must also be considered, because citizens are likely to consume political information both on television and newspapers. For example, among consumers of both mediums, the visual effects of heavy television consumption may be counterbalanced by the equally heavy consumption of textual information in the newspapers. According to this rationale, the relationship of interest may then be better captured by the difference in voters' degree of consumption of visual versus text-based information or personalized versus nonpersonalized information. Such possibility has not always, nor often, been explored in the relatively scant number of studies addressing the relationship between media exposure and leader effects on voting behavior, focusing primarily on the U.S. case.

In their seminal analysis, McLeod et al. (1983) show that television-reliant voters are those with the highest likelihood to use candidate image characteristics in making their voting choices. Keeter's (1987: 344) longitudinal analysis of American National Election Study data sets collected between 1952 and 1980 supports McLeod et al.'s findings and concludes that "television has facilitated and encouraged vote choices based on candidates' personality assessments." Holian and Prysby (2014) further extend the time frame of Keeter's analysis and again find strong effects of television exposure on patterns of candidate-centered voting.

Quite unlike the case of the United States, however, single-country analyses of European parliamentary democracies do not provide unequivocal support for the notion that party leaders matter more for regular consumers of televised political news. Mughan's (2000) seminal analysis of British parliamentary elections concludes that increasing use of television for political information is indeed correlated with greater leader effects. His conclusions, however, find only partial support in Rico's (2014) analysis of three Spanish elections, and no support whatsoever in Elmelund-Præstekær and Hopmann's (2012) study of preferential voting in Danish local elections. Takens et al.'s (2015) analysis of the Dutch election of 2010 provides more convincing evidence in support of the link between exposure to political information on television and the personalization of voting behavior. More recently, Garzia (2017b) found evidence of the dominance of leader effects among voters exposed mainly to televised political information in the 2013 Italian Parliamentary Election.

So far, only one study by Gidengil (2011) tackled the issue from a comparative perspective. As the author concludes, "leader effects actually seemed to be weaker for voters who had the highest levels of television exposure" (Gidengil 2011: 154). Yet, as Gidengil (2011: 154) admits, exposure to television

is not really the most appropriate variable for testing whether leaders matter more to people who are regular viewers... A more appropriate test of the hypothesis would be to focus on voters whose main source of information was television news. 
Furthermore, her study is not complemented by the consideration of possible equal consumption of political information on newspapers, because a mixed media diet may potentially neutralize or counterbalance the candidate priming and framing effects of television.

This article builds on these insights and contributes to the existing literature in a threefold way. First, we investigate the connection between media exposure and the determinants of voting behavior over the largest pool of countries and elections considered so far. This allows us to unfold systematic media effects regardless of crossnational variations in terms of institutional arrangements, media, and party systems. Second, we rely on measures of exposure to political information in the media. In this way, we can remove the noise induced by news-avoiding media users. Third, we depart from an approach focusing on exposure to different media in isolation. Media types are not equally relevant for predicting leader effects. While television primes politicians' image, newspapers primarily convey non-visual content that can be assumed to hinder personality evaluations. For this reason, we make use of a compositional measure that considers voters' television diet in relation to their newspapers' reading habits, as we shall explain below.

\section{Patterns of News Consumption in Thirteen Parliamentary Democracies}

The lack of suitable cross-national data sets has thus far hindered comparative research in this domain. Existing surveys either overlooked leader evaluations (i.e., European Election Study) or voters' exposure to political information in the media (i.e., Comparative Study of Electoral Systems). Arguably, this lack of appropriate data sources has posed the greatest obstacle to a comparative analysis of the mediator role of exposure to political information in the media on the emergence of personalized voting behavior. Against this background, we conducted a large-scale harmonization effort pooling forty-eight national election studies collected in thirteen West European parliamentary democracies during the period 1982-2016. This set of elections includes all available West European election studies featuring the key variables of interest to address our research question (i.e., party leader evaluations and measures of exposure to political news in different types of media). Table 1 presents the full list of countries and elections included in the analysis (detailed study descriptions are presented in Supplemental Appendix A1).

It is worth noting that such measures have been introduced in national election studies relatively late, compared with the development of mass communication in western democracies. Indeed, items tapping individuals' frequency of consumption of political information on the media were absent from European national election studies until the 1980s. By then, television had already penetrated western societies to a large extent (Ohr 2011). Despite such caveat, our data set offers, to the best of our knowledge, the most comprehensive set of election studies ever considered in studying the relationship between exposure to political information and the determinants of vote choice. This 
Table I. Detailed List of National Election Studies Included in the Analysis.

\begin{tabular}{llllr}
\hline AT20I3 & DK20II & IE2007 & NLI998 & SEI988 \\
$\mathrm{CH} 2003$ & ELI996 & ITI990 & NL2002 & SEI99I \\
$\mathrm{CH} 2007$ & ES2000 & ITI996 & NL2006 & SEI994 \\
$\mathrm{CH} 201 \mathrm{II}$ & ES2008 & IT200I & NL20I0 & SEI998 \\
$\mathrm{CH} 2015$ & ES20II & IT2006 & PT2002 & SE2002 \\
DE2002 & ES20I5 & IT2008 & PT2005 & SE2006 \\
DE2009 & ES20I6 & IT20I3 & PT2009 & SE20I0 \\
DE20I3 & FI2003 & NLI986 & PT20I5 & UK20I5 \\
DK2005 & FI2007 & NLI989 & SEI982 & \\
DK2007 & FI20II & NLI994 & SEI985 & \\
\hline
\end{tabular}

Note. $\mathrm{AT}=$ Austria; $\mathrm{CH}=$ Switzerland; $\mathrm{DE}=$ Germany; $\mathrm{DK}=$ Denmark; $\mathrm{EL}=$ Greece; $\mathrm{ES}=$ Spain; $\mathrm{FI}=$ Finland; IE = Ireland; IT = Italy; NL = The Netherlands; PT = Portugal; SE = Sweden; UK = The United Kingdom.

large- $N$ comparative analysis of thirteen parliamentary democracies in Western Europe covers forty-eight elections held in nearly four decades, thus offering a substantial improvement to the scope of preexisting research on this topic.

Another virtue compared with previous research stems from our improved measurement strategy. Our measurements correspond to a previously defined core conceptual definition that does not contemplate the sacrifice of conceptual homogeneity. Indeed, every study included in the analysis contains measures of media exposure that allow the respondent to (1) indicate a frequency of the media usage, (2) explicitly mention media usage for political information, and (3) include both television and newspapers. Second, we allow for different measurement scales ranging from more fine-grained measures, such as those allowing respondents to report news exposure on a given media in number of days per week, to a minimally satisfactory scale (e.g., four values ranging from "never" to "every day") to extend the pool of studies included. Detailed question wording, answer categories, and recoding strategy for our newspapers and television items are presented in Supplemental Appendices A2 and A3, respectively. Our minimum-common-denominator approach grounds on the idea that - whatever the answer categories - every respondent can be classified in terms of what media (if any) represents their most important source of political information. Figure 1 provides a cross-time description of the percentage of individuals reporting to use either newspapers or television, as well as both combined, as daily sources of political information.

The role of newspapers as information providers has been virtually unchanged over the three and a half decades depicted in the figure. However, it seems plausible that newspaper consumption may have suffered a decline as a result of the emergence of television, which we cannot capture due to the time frame constraints imposed by the unavailability of media exposure data before the 1980s. Nonetheless, we can highlight the sustained importance of newspapers as a source of daily political information for about a quarter of the electorate over the time frame under analysis. 


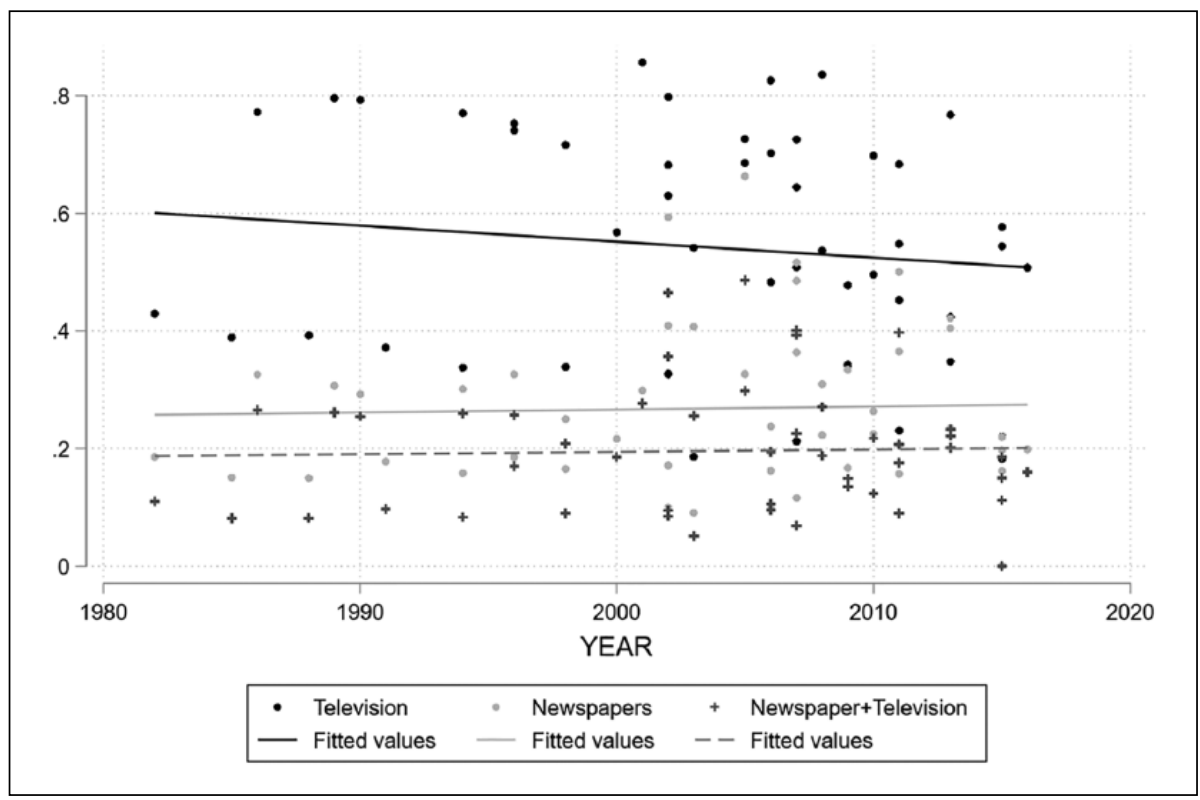

Figure I. Newspapers and television as a daily source of political information (\%). Note. Plot entries represent the proportion of respondents in each survey consuming newspapers and television news always/every day.

The same data constraints apply to television. By the 1980s, television had already achieved a dominant position within western societies and their politics. Therefore, to capture any noticeable temporal variation in exposure patterns, our data would likely need to include previous decades. In the current time frame, if any variation is registered is a slight decline in television consumption of political information toward the later years, possibly resulting from the increasing importance of online political information. Nevertheless, television is still, by and large, voters' preferred source of information about politics.

Still, these categories are not exclusive - voters can often be exposed to political information, both on television and newspapers. Insofar as television pervaded in modern societies, much any frequent consumer of political information is prone to be exposed to it - even if not necessarily exclusively - through television. Therefore, separately analyzing patterns of consumption of either media is possibly not the most informative strategy to understand their relative weight as news providers.

As the lack of appropriate measures of voters' exposure to political information in the media has been one of the main problems identified in previous studies, special attention was given to the design of this type of measurement in the present study. In concrete, we have taken a careful reflection about composition rather than the mere quantity of media usage. This allows for the consideration of the possible overlap in the exposure to different media for political information. This approach carries two 
main advantages. First, it allows for the consideration of the possible overlap between the consumption of political information in different mediums. For example, cognitively mobilized citizens are arguably more interested in politics and, as such, are more prone to self-selection into multiple media sources, potentially with high levels of consumption. It is a well-established finding in political communication research that more educated and more interested citizens are major news consumers (Boulianne 2011; Strömback et al. 2013; Strömback and Shehata 2010). Therefore, for these individuals, the visual effects of heavy television news exposure may be compensated by an equally frequent newspaper readership. Inversely, among citizens with low levels of education or interest in politics, even only occasional exposure to television may have substantial effects if not counterbalanced by newspaper consumption. Second, but not least importantly, a compositional approach relaxes concerns related to overreporting of news exposure, either originating from social desirability bias or inability to correctly recall previous media consumption (Prior 2009). Amplified self-reports of news exposure would not affect our measure, assuming they are proportionally balanced for television and newspapers.

On these bases, we now concentrate on the proportion of individuals equally highly exposed to political information in both newspapers and television. These heavy political news consumers remain stable at about 20 percent of the electorate throughout the whole period under analysis. These individuals are essential to grasping the different preponderance of each media in the composition of individuals' sources of political information. To be sure, if we have noted that about 25 percent of individuals are highly exposed to political information on the newspapers, 20 percent are highly exposed to political information on both newspapers and television. That is, among regular newspaper readers, nearly 80 percent also consume television news frequently. This group has thus a balanced media diet, because it is equally composed of the two mediums. In contrast, only one-third of regular TV news watchers are frequent readers of politics in the newspapers. In other words, there are significantly more individuals exposed to political information exclusively through television. This has implications regarding the relative effects of image and text, as previously discussed. Whereas in a balanced media diet image and text may cancel each other out, whenever one prevails - which we have concluded to be mostly image - it will bear a disproportionate effect over individuals' political reasoning. These arguments make a case for going beyond the consideration of the mere frequency of news exposure and also taking into account the composition of individuals' media diets.

In a comparative study of news consumption gaps, Shehata and Strömback (2011) distinguish between Newspaper- and Television-Centrism. The authors identify this environmental characteristic as the critical determinant of news consumption at the individual level, due to contagion and socialization processes. They operationalize it as the difference between the average amount of total newspaper reading minus the average amount of total television viewing for each of the countries under analysis. We apply the same logic to develop a measure of "Newspaper/Television-Centrism" at the individual level, assigning values -1 (newspaper-centric respondent) to individuals more frequently exposed to political information on newspapers than television, 0 
Table 2. Construction of the Newspaper/Television-Centrism Typology.

Newspaper Consumption

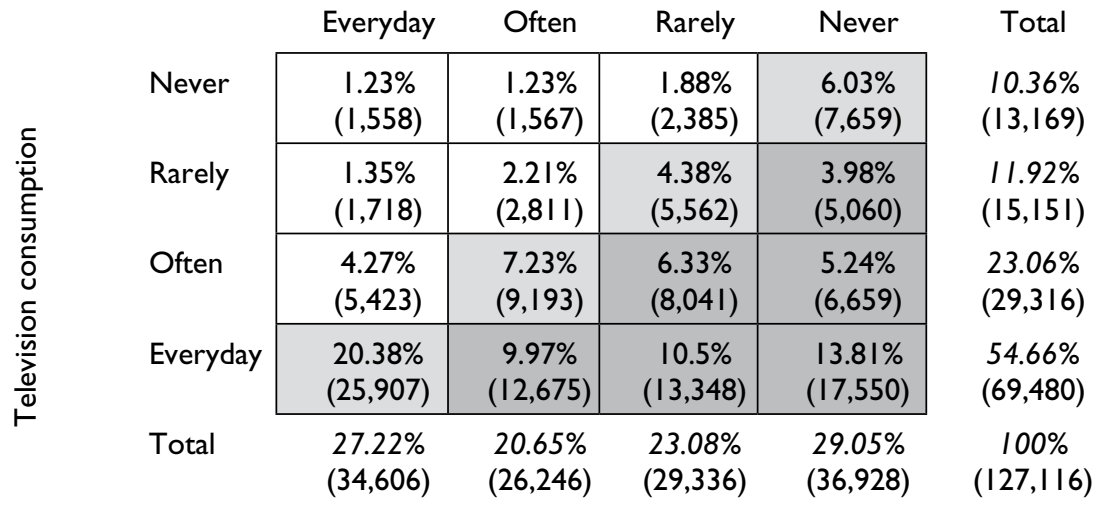

Newspaper-Centric

Balanced

Television-Centric.

(balanced consumption of newspapers and television news) to individuals reporting the same frequency of news collection for newspapers and television, and +1 for television-centric respondents, more frequently collecting news over television rather than reading newspapers. In this framework, we thus hypothesize that party leader evaluations matter more for vote choice among the latter group.

Table 2 illustrates the construction of the Newspaper/Television-Centrism typology, displaying the distribution of respondents across different levels of exposure to political information on television and in the newspapers. The preponderance of television-centric individuals in our sample becomes evident from the table, reflecting the more important role of television as a source of voters' political information over the last decades.

In the typology presented in the table, 12 percent of individuals are newspapercentric while about 50 percent of the sample is television-centric. Furthermore, only one respondent out of five balances a heavy (i.e., daily) television news consumption with an equally heavy exposure to political news in the newspapers. Such figures are illustrative of the disproportionate weight of audiovisual over printed political information in individuals' media diet. If, as discussed before, an audiovisual type of political information primes candidates and political decisions based on image considerations, as well as assessments of individual political actors, the differences in media diets observed may have significant consequences on voting behavior-an empirical issue to which we now turn to by means of multivariate statistical techniques.

\section{News Media Consumption and Party Leader Effects on Voting Behavior}

Our statistical analysis investigates the extent to which individual patterns of exposure to political information in different media moderate the effect of leader evaluations on 


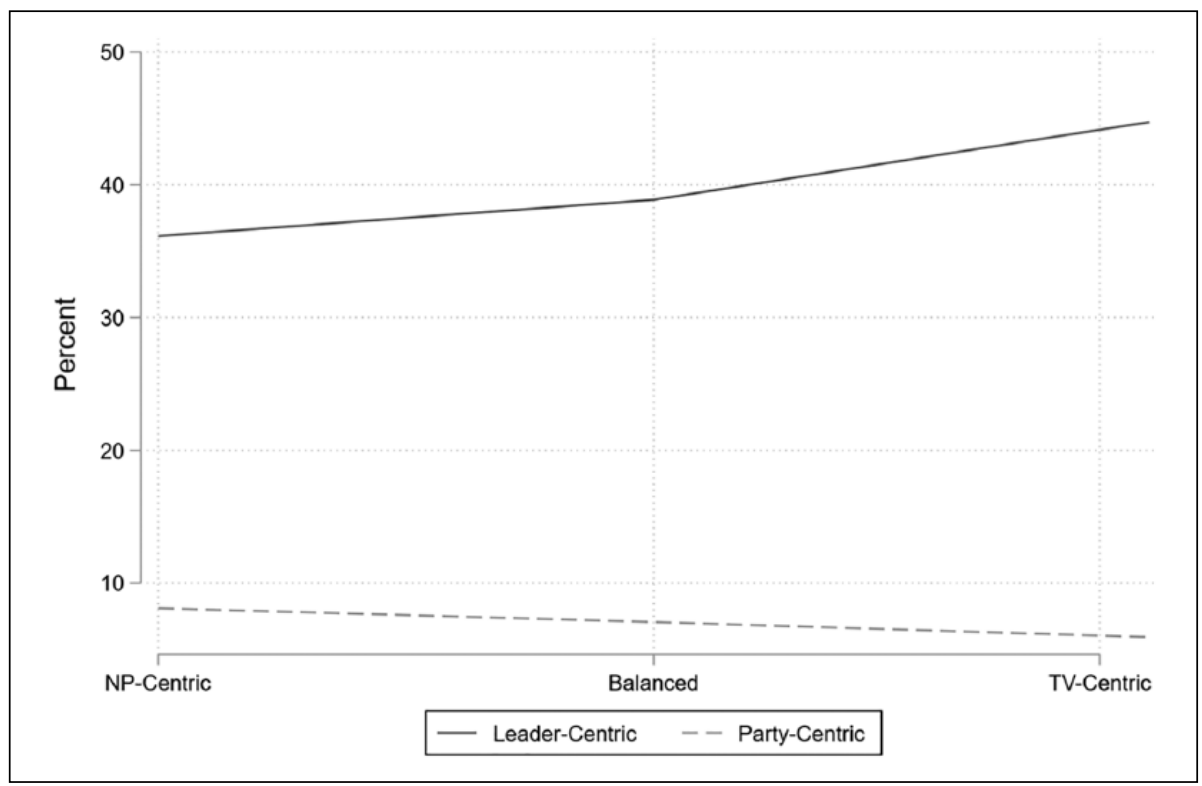

Figure 2. Distribution of party-centric and leader-centric voters across varying levels of Newspaper/Television-Centrism.

individuals' vote choice. In line with the theoretical framework laid out, we expect that a television-centric media diet leads to stronger leader effects on the vote. Such proposition can be preliminarily assessed by means of the analysis of the relationship between Newspaper/Television-Centrism and different patterns of voting behavior. To this purpose, we have initially decomposed our sample into the share of respondents who voted for the party they declare to identify with despite not being the party of their best rated leader (i.e., party-centric voters) and the share of individuals who declare to have voted for the party of their highest rated leader without identifying with that party (i.e., leader-centric voters). The distribution of these two categories across levels of our Newspaper/Television-Centrism index confirms our initial expectations (see Figure 2). Regardless of the disproportionate weight of television-centric voters vis-àvis newspaper-centric voters in our sample, a television-centric media diet appears more common among leader-centric voters. Such preliminary evidence is informative about the relationship between voters' media diet and their voting behavior patterns but requires further empirical analysis.

To estimate the impact of party leader evaluations in a multivariate model of vote choice, we rely on party leader thermometer scores ranging from 0 (dislike) to 10 (like), because this is the most widely available measure in the election studies at hand (see Supplemental Appendix A4 for details on the leader evaluation items). The effect of party leaders is tested against two crucial attitudinal determinants of vote choice recurrently present in voting behavior models: partisanship and ideological proximity. 
We tackle the former through a measure of respondents' feelings of closeness to a political party ranging between (0) not close to the party, (1) only a sympathizer, (2) close to the party, and (3) very close to the party. This measure is widely available in European election studies, and it signals a long-term affective relationship which can be meaningfully distinguished from vote choice (Dalton 2008). To measure ideological proximity in comparative perspective, we follow Inglehart and Klingemann (1976) and rely on the absolute value of the party-respondent distance on the 10-point leftright scale.

Regarding modeling strategy, varying choice sets (i.e., the change in the composition of party systems across countries and/or time) pose a severe challenge in modeling vote choice in a comparative, longitudinal setting. To alleviate this problem, we initially overimpose a fixed choice set within a conditional logit framework. To fit our conditional logit models, we have classified party choice into the four main party families available to voters in virtually every country and election under analysis (from left to right: Far Left, Social-Democrats, Conservative/Christian, and Conservative/Liberals), ${ }^{3}$ and then recoded the voting variable accordingly. We acknowledge the existence of differences and transformations in the composition of these party families over the last century. For this reason, we have analyzed each party family independently concerning its consistency across time and countries - no reason for significant concerns emerged. ${ }^{4} \mathrm{~A}$ full list of the classification by party family over country and election study is available in Supplemental Appendix A5.

The core logic underlying our theoretical argument can be subsumed into the following proposition: A television-dominated media diet primes leader effects on vote choice, whereas a newspaper-dominated media diet hinders them. To test this proposition, we estimated conditional logit models to measure the mediating role of exposure to political information on television/newspapers on leader effects (Models 1 and 2). The key covariates included in the model (i.e., strength of partisanship, ideological proximity, and leader evaluations) are measured at the Respondent $\times$ Party Level, while control variables (i.e., age, gender, educational level, interest in politics, exposure to political information on newspapers and television, and score on the Newspaper/ Television-Centrism index) are measured at the respondent level (coefficients are not shown for parsimony; for full estimation details, see Supplemental Appendix A6). The first two columns of Table 3 present the results.

Model 1 is the baseline model, where the relative impact of the key predictors on vote choice is tested. Standardized conditional logit estimates show the slight dominance of leader evaluations over partisanship and ideological proximity - a finding in line with the extant literature (Garzia 2017b). Model 2 addresses more directly the research question about the influence of a television-based media diet on leader effects, by adding an interaction term between leader evaluations and the Newspaper/ Television-Centrism measure. The interaction term is positive and significant, suggesting that a more television-centered media diet fosters leader effects on vote choice.

Albeit informative, our conditional logit models are unable to fully take into account the varying choices available to voters across, and even within, countries. ${ }^{5}$ Moreover, a conditional logit framework cannot account for the substantial number of 
Table 3. Leader Evaluation and Newspaper/Television-Centrism: Interaction Models.

\begin{tabular}{|c|c|c|c|c|}
\hline & \multicolumn{2}{|c|}{$\begin{array}{l}\text { Conditional Logit (Four } \\
\text { Main Party Families) }\end{array}$} & \multicolumn{2}{|c|}{$\begin{array}{c}\text { Stacked Data Matrix (All } \\
\text { Parties) }\end{array}$} \\
\hline & $(\mathrm{I})$ & $(2)$ & (3) & (4) \\
\hline \multicolumn{5}{|l|}{ Respondent $\times$ Party-Level Covariates } \\
\hline Leader evaluation & $\begin{array}{l}1.268 * * * \\
(0.0183)\end{array}$ & $\begin{array}{l}1.273 * * * \\
(0.0184)\end{array}$ & $\begin{array}{l}1.044 * * * \\
(0.0086)\end{array}$ & $\begin{array}{l}1.047 * * * \\
(0.0086)\end{array}$ \\
\hline Partisanship & $\begin{array}{l}0.927 * * * \\
(0.0125)\end{array}$ & $\begin{array}{l}0.927 * * * \\
(0.0125)\end{array}$ & $\begin{array}{l}0.747 * * * \\
(0.0062)\end{array}$ & $\begin{array}{l}0.748^{* * *} \\
(0.0062)\end{array}$ \\
\hline Ideological proximity & $\begin{array}{l}0.974 * * * \\
(0.0144)\end{array}$ & $\begin{array}{l}0.976 * * * \\
(0.0145)\end{array}$ & $\begin{array}{l}0.958^{* * *} \\
(0.0093)\end{array}$ & $\begin{array}{l}0.958 \text { *** } \\
(0.0093)\end{array}$ \\
\hline \multicolumn{5}{|l|}{ Cross-level interaction } \\
\hline $\begin{array}{l}\text { Leader Evaluation } \times \text { Newspaper/ } \\
\text { Television-Centrism }\end{array}$ & - & $\begin{array}{l}0.0993 * * * \\
(0.0160)\end{array}$ & - & $\begin{array}{l}0.0772 * * * \\
(0.0077)\end{array}$ \\
\hline Log likelihood & $-22,4 \mid 4.503$ & $-22,391.159$ & $-103,085.53$ & $-103,037.8$ \\
\hline Wald $\chi^{2}$ & $17,063.37$ & $17,063.89$ & $52,911.95$ & $53,045.51$ \\
\hline $\mathrm{AIC}$ & $45,137.0$ & $45,092.3$ & $203,996.3$ & $197,795.3$ \\
\hline $\mathrm{BIC}$ & $46,7 \mid 4.3$ & $46,679.8$ & $204,183.0$ & $198,003.5$ \\
\hline$n$ (respondents) & 207,322 & 207,322 & 439,329 & 439,329 \\
\hline n (observations) & 58,945 & 58,945 & 127,779 & 82,339 \\
\hline
\end{tabular}

Note. Cell entries are standardized logistic regression estimates. Standard errors (in parentheses) are clustered robust at the respondent level. All models include year and country fixed effects. Respondentspecific controls (age, gender, education, political interest, newspaper consumption, television consumption, and score on the Newspaper/Television-Centrism index) are included, but coefficients are not shown for parsimony. Full estimation is presented in Supplemental Appendix A6. AIC = Akaike information criterion; $\mathrm{BIC}=$ Bayesian information criterion.

$* * * p<.001$.

votes cast in favor of parties beyond these four party families - something we cannot model within the overreaching approach necessary to specify our conditional logit models. For these reasons, we considered an additional modeling strategy that relaxes the assumption of homogeneous choice sets by estimating random-intercept logistic regression models using a "stacked" data matrix. In this design, the dependent variable (vote choice) does not consist of nominal categories represented by the several parties running for election in a country in an election-year, but becomes a binary choice $(0=$ did not vote for this party, 1 = voted for this party) of vote for a generic party, repeated as many times per respondent as the number of parties contesting that specific election. This option has the advantage of not restricting the analysis to specific party families, allowing for the consideration of vote choices for any of the political parties available. ${ }^{6}$ The results, in Models 3 and 4 of Table 3, largely corroborate the conditional logit analysis. In Model 3, leader evaluations stand out again as the most relevant predictor of vote choice. In Model 4, the interaction term between leader evaluations and Newspaper/Television-Centrism is included. It remains positive and 


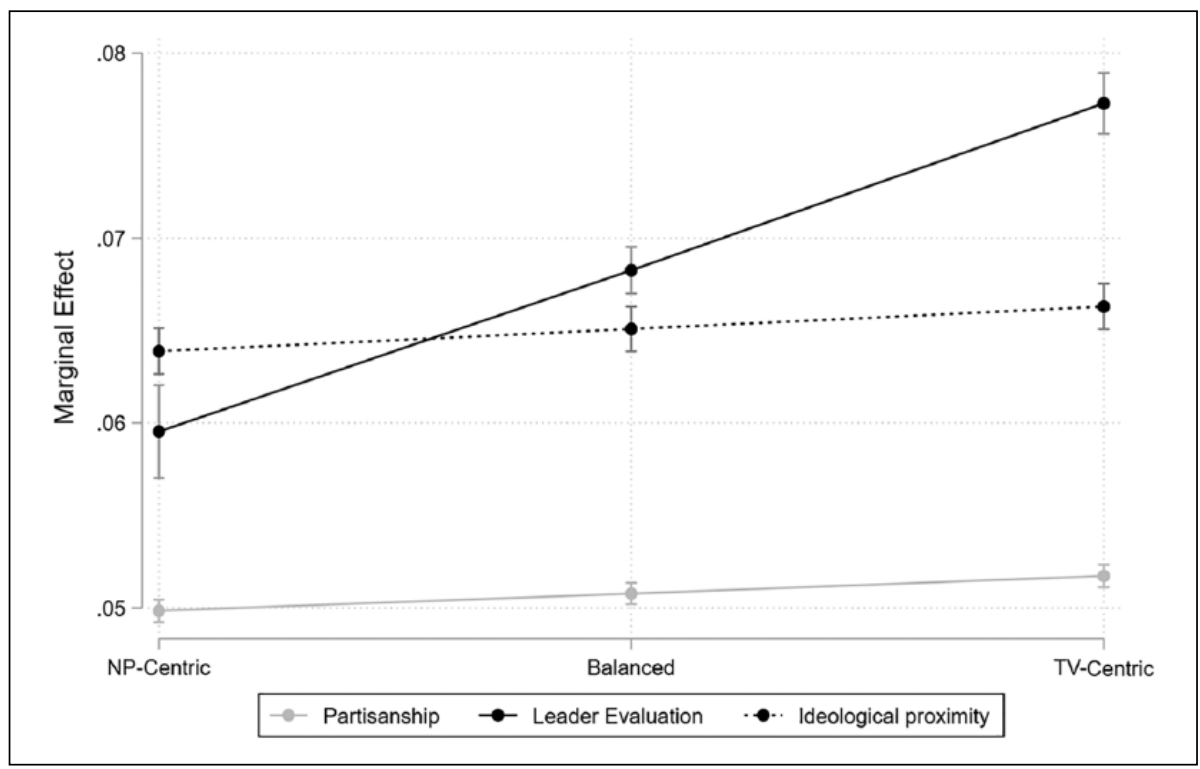

Figure 3. Marginal effect of key predictors across values of the Newspaper/TelevisionCentrism index.

statistically significant with only minor changes in effect size. To better grasp the differentiated effects of leaders across levels of Newspaper/Television-Centrism, Figure 3 plots the marginal effect of our key predictors (estimates are based on Model 4; Table 3).

Figure 3 shows a stronger effect of voters' evaluations of party leaders on vote choices according to individuals' media diet. For newspaper-centric individuals, of all three predictors, ideological proximity is the strongest. For individuals with a balanced media diet, leader effects increase in importance but are yet undistinguishable in magnitude from the effects of ideological proximity. For television-centric individuals, however, leader evaluations stand out as the strongest predictor of vote choice, surpassing the effects of ideological proximity. Noticeably, both ideological proximity and partisanship remain fairly stable in the magnitude of their effects regardless of the individuals' media diet. This confirms the privileged impact of television specifically over leader effects, providing further evidence in support of the theoretical relationship between the expansion of television and the personalization of politics.

\section{Robustness Tests}

We have checked the robustness of these findings using different strategies. We initially resorted to Leave-One-Out Cross Validation (LOOCV). First, election studies were alternatively excluded one by one from the sample, to inspect if an outlier could 
be driving the trend. No differences were found. Second, we carried a more demanding test, by repeating the same procedure for countries, excluding them one at the time from the sample and re-estimating the interaction models. No country was found to affect the significance nor the sign of the interaction term. The effect size also remains virtually unaltered. As a third, even more demanding test, we excluded in turn the countries belonging to each of the three types of media systems identified by Hallin and Mancini (2004). The results provide further support to the idea that our findings are robust to case selection and are not driven by an outlier country or a distinctive media system arrangement. The results of these tests are presented in Table A7 of the Supplemental Appendix.

In addition, we specified additional hierarchical logit models (HLMs) for each of the four party families alternatively, to exclude the possibility that the results are driven by disproportionate leader effects in one party family. Again, no significant differences were found, signaling a generalized trend that is not contingent on any specific party family. Across all party families, leader effects are consistently stronger among television-centric individuals. The full model results are available in Table A8 of the Supplemental Appendix.

Finally, we checked the robustness of our measurement strategy by testing an alternative measurement of the Newspaper/Television-Centrism index. Instead of the 3 -point scale used throughout the article $(-1=$ newspaper-centric, $0=$ balanced, $1=$ television-centric), we resort to the simple difference between the original variables tapping respondents' frequency of consumption of political news on the television and newspapers $(1=$ never, $2=$ rarely, $3=$ often, $4=$ always $)$. This originates a 7 -point Newspaper/Television-Centrism index that directly results from the subtraction of the newspaper consumption from the television consumption variable. We have re-estimated all models by interacting leader evaluations with the 7-point scale in place of the 3-point index originally employed. The results are available in Table A9 of the Supplemental Appendix.

\section{Discussion and Conclusion}

This study's results go beyond preexisting literature by providing an improved measurement and conceptualization of voters' exposure to political information in oldmedia platforms and its relationship to voting behavior patterns. The breadth of countries considered constitutes an unprecedented comparative effort to systematically analyze how the dominant role of television as a source of political information provides the ideal setting for the development of the personalization of politics at the electoral level. In specific, we offered three advancements versus previous studies: a large- $N$ comparative analysis spanning over four decades, measures of frequency of exposure to political information in both newspapers and television, and a new compositional measure of voters' media diet. Significantly, the results do not seem to be driven by the specificities of media systems, party systems, or countries' institutional arrangements but fitting into a pattern common to Western European parliamentary democracies. In particular, we shed light on two underappreciated dimensions of the 
relationship between media exposure and personalized voting behavior. First, we highlight that this connection has characterized political decisions over the last four decades. Second, we show that to fully appreciate the impact of television on the determinants of vote choice, it is necessary to consider the wider media diet of the voters explicitly, computing the proportion of televised (audiovisual) exposure over (nonaudiovisual) newspaper exposure.

A methodological limitation of this study is worth mentioning. Having relied on quantitative measures of exposure to newspapers and televised political information, our measures are admittedly imperfect. As we have no information on media content, we cannot be sure of the extent to which individuals were exposed to party leaders' images on the different media. Carrying a media content analysis for the entirety of our period of analysis would be unfeasible, given the obstacles for data collection (Nai 2018). For the same reason, longitudinal media content analyses, particularly regarding television, are also extremely rare. As of today, the single longitudinal case study of Germany found evidence supporting a personalization in televised media content (Schulz et al. 2005). Given the inexistence of longitudinal accounts of media content in televised news, we have relied on other studies suggesting, alternatively, a comparison between different media (van Aelst et al. 2011), under the assumption that television coverage provides a type of communication more centered on leaders than in newspapers, as a result of the different nature of these platforms (Salgado 2007; van Aelst 2007). We substantiate the findings of these studies when it comes to voting behavior, demonstrating that the distinct characteristics of these two media yield different patterns of voting, with television, in particular, favoring a personalized voting behavior. In turn, this bears normative implications. The mediatization of politics through televised political communication led, among others, to the development of increasingly personalized electoral campaigns, the consideration of particular qualities in the candidates running for office, and further attention to aspects pertaining to intimization or privatization (Sheafer 2001; van Aelst et al. 2011). These developments may progressively contribute to stronger attention from voters to superficial personal aspects of electoral candidates rather than substantial political qualities. In fact, a number of empirical studies point in this direction, by asserting that television-reliant voters are more likely to take into account politicians' personality traits related to affective, noncompetence-related dimensions (Lenz and Lawson 2011).

When it comes to the implications of our findings for the study of media effects in the age of online campaigning, social media, and information bubbles, we argue in favor of their timeliness. Indeed, we believe that understanding the effects of the composition of media usage patterns on electoral mechanisms will become even more pressing in the future. Andrew Chadwick highlights that a key persistent feature of media systems, of all media systems, is hybridity. As he puts it, "all older media were once newer and all newer media eventually get older. But older media of any consequence are rarely entirely displaced by new media" (Chadwick 2013: 24). In other words, it may be analytically inconclusive, and even conceptually inaccurate, to gauge a medium in isolation. Nowadays, only a minority of voters collect political 
information exclusively on traditional media platforms. Most voters today rather gather information from new and old media, mixing sources in a way that is consonant with their preferences, use intentions, and taste. Moreover, research on social media usage reveals the wide heterogeneity of users in terms of personality traits (Zhong et al. 2011), cultural values (Lewis and George 2008), and age difference (Yamamoto et al. 2015). Thus, hybridization of the media environment and users' heterogeneity favor the diffusion of variegated patterns of usage of new media tools. The diffusion of the Internet as a provider of political information intertwines visual and non-verbal communication in much harder-to-disentangle patterns of content exposure. In this sense, our findings speak to the necessity to understand the respective effects of visual versus textual communication brought about by online information providers (old and new). As of today, assessing the actual individual-level effect of these new patterns would require a whole new set of measures that may track the specific content of new media usage. For instance, when it comes to politics, are Facebook users using Facebook to read posts or rather to watch Facebook live streaming videos? Are newspaper websites' readers actually reading the news or just watching the larger amount of video content offered by these sites? Current survey measures hosted in election studies cannot disentangle these patterns. Similar measurement difficulties have been raised for traditional media as well (Goldman et al. 2013; Prior 2013) and, clearly, there is no ideal solution in all respects so one has to weight pros and cons of measurement strategies. New techniques gathering browsing data (Guess 2014) may provide more fine-grained measures in the specific usage of new media, but no electoral survey has included this type of data so far. For the moment, we can only speculate that acknowledged mechanisms of self-selection into the content, activated and made widespread by the extremely high-choice character of new media, will further reinforce the heterogeneity in voters' decision making. Much like contemporary fragmented media environment is leading to a deepened political knowledge gap and to more polarized attitudes' distributions in the electorate, the ability to self-select into visual or written content will reinforce the voters' decisional mechanisms. The extent to which this is - or will be - the case represents an obvious avenue for future research at the crossroad between party competition, political communication, and electoral research.

\section{Declaration of Conflicting Interests}

The author(s) declared no potential conflicts of interest with respect to the research, authorship, and/or publication of this article.

\section{Funding}

The author(s) disclosed receipt of the following financial support for the research, authorship, and/or publication of this article: We gratefully acknowledge the financial support of the Swiss National Science Foundation (Grant Number: PZ00P1167997).

\section{ORCID iD}

Diego Garzia (iD) https://orcid.org/0000-0001-8767-4099 


\section{Supplemental Material}

Supplemental material for this article is available online.

\section{Notes}

1. On these bases, this paper focuses explicitly on the micro-level behavioral dimension of personalization rather than on media personalization, that is, the degree of personalization in newspapers/television coverage (Rahat and Kenig 2018).

2. We performed an exploratory analysis of the few available election studies conducted in Western Europe and featuring a detailed analysis of media content over the campaign (i.e., Austrian National Election Study 2013 and German Longitudinal Election Study 2009/2013). The results of the comparison of party leader mentions on television and in the newspapers unanimously point to a greater degree of personalized media coverage on television news.

3. This scheme follows a pragmatic logic of complexity reduction. We are aware of the potential internal heterogeneity of these categories and still defend this decision on three main grounds. First, these categories broadly correspond to long-standing divisions mapping common socio-structural cleavages. Second, in many cases, a finer grained classification would have led to an unbearable amount of missing values due to the different party system configurations in the various countries. Third, we operated an extensive array of robustness tests including Leave-One-Out (LOO) tests sequentially excluding party families and showing no substantial impact on our findings. We based our codes of party families on the classification provided by the Comparative Manifesto Project.

4. Social-Democratic parties are available in each and every election study. In twelve out of thirteen countries, they are always the same party-the only exception is Italy. Christian/ Conservative parties are present in forty-seven out of forty-eight elections. They are consistent across time in every country except Italy. Liberal/Conservative parties are consistent in ten out of thirteen countries. They vary across time in Italy and Spain and are systematically missing in Greece. Overall, they are present in forty-two elections out of forty-eight. Far-Left parties are consistent in nine out of twelve countries, with cross-time variation in Italy, Germany, and Spain. They are systematically missing in Switzerland. In total, they are present in forty-one out of forty-eight elections.

5. In particular, varying choice sets threaten the Independence of Irrelevant Alternatives assumption that is invoked in conditional logit models (including our application). Relaxing this assumption required modeling the variations in the choice sets. Therefore, we experimented with versions of conditional logit models that allow for variation in voters' choice sets by interacting a choice set indicator with each alternative-specific covariate (i.e., leader evaluations, partisanship, ideological proximity). This produces estimates that are choice set specific, but this comes at the cost of misleading generalizations. For instance, the choice set configurations usually involve one or two specific countries and therefore convey the effect of idiosyncratic context rather than the absence or presence of certain party families. Moreover, these models involve unbearable complexity.

6. Note that this strategy comes at the risk of underspecification by not including respondentspecific controls, which do not have a direct counterpart at the Respondent $\times$ Party Level (e.g., socio-demographics), and therefore cannot be meaningfully estimated under such framework. 


\section{References}

Aaldering, Loes. 2018. "The (Ir)rationality of Mediated Leader Effects." Electoral Studies 54:269-80.

Altheide, David L., and Robert P. Snow. 1979. Media Logic. London: Sage.

Boulianne, Shelley. 2011. "Stimulating or Reinforcing Political Interest: Using Panel Data to Examine Reciprocal Effects between News Media and Political Interest." Political Communication 28 (2): 147-62.

Chadwick, Andrew. 2013. The Hybrid Media System: Politics and Power. Oxford: Oxford University Press.

Dalton, Russell J. 2008. Citizen Politics. Thousand Oaks, CA: CQ Press.

Dalton, Russell J., David M. Farrell, and Ian McAllister. 2011. Political Parties and Democratic Linkage. Oxford: Oxford University Press.

Dalton, Russell J., Ian McAllister, and Martin P. Wattenberg. 2000. "The Consequences of Partisan Dealignment." In Parties without Partisans, ed. Russell J. Dalton and Martin P. Wattenberg, 37-63. Oxford: Oxford University Press.

Druckman, James N. 2003. "The Power of Television Images: The First Kennedy-Nixon Debate Revisited." The Journal of Politics 65 (2): 559-71.

Elmelund-Præstekær, Christian, and David Hopmann. 2012. "Does Television Personalise Voting Behaviour? Studying the Effects of Media Exposure on Voting for Candidates or Parties." Scandinavian Political Studies 35:117-40.

Garzia, Diego. 2014. Personalization of Politics and Electoral Change. Basingstoke: Palgrave Macmillan.

Garzia, Diego. 2017a. "Voter Evaluation of Candidates and Party Leaders". In The SAGE Handbook of Electoral Behaviour, ed, Kai Arzheimer, Jocelyn Evans and Michael S. Lewis-Beck, 633-53. Thousand Oaks, CA: Sage.

Garzia, Diego. 2017b. "Personalization of Politics between Television and the Internet: Leader Effects in the 2013 Italian Parliamentary Election." Journal of Information Technology \& Politics 14 (4): 403-16.

Gidengil, Elizabeth. 2011. "Voter Characteristics and Leader Effects." In Political Leaders and Democratic Elections, ed. Kees Aarts, André Blais, and Hermann Schmitt, 147-64. Oxford: Oxford University Press.

Goldman, Seth K., Diana C. Mutz, and Susanna Dilliplane. 2013. "All Virtue Is Relative: A Response to Prior." Political Communication 30 (4): 635-53.

Guess, Andrew M. 2014. "Measure for Measure: An Experimental Test of Online Political Media Exposure.” Political Analysis 23 (1): 59-75.

Hallin, Daniel C., and Paolo Mancini. 2004. Comparing Media Systems. Cambridge: Cambridge University Press.

Hayes, Danny. 2009. "Has Television Personalized Voting Behavior?" Political Behavior 31 (2): 231-60.

Holian, David B., and Charles L. Prysby. 2014. Candidate Character Traits in Presidential Elections. New York: Routledge.

Holmberg, Sören, and Henrik Oscarsson. 2011. "Party Leader Effects on the Vote.” In Political Leaders and Democratic Elections, ed. Kees Aarts, André Blais, and Hermann Schmitt, 35-51. Oxford: Oxford University Press.

Inglehart, Ronald \& Hans-Dieter Klingemann. 1976. "Party Identification, Ideological Preference and the Left-Right Dimension Among Western Mass Publics". In Party Identification and Beyond: Representations of Voting and Party Competition, ed. Ian Budge, Ivor Crewe and Dennis Farlie, 243-73. London: John Wiley. 
Karvonen, Lauri. 2010. The Personalisation of Politics. Colchester, UK: European Consortium for Political Research Press.

Keeter, Scott. 1987. "The Illusion of Intimacy: Television and the Role of Candidate Personal Qualities in Voter Choice." Public Opinion Quarterly 51:344-58.

Langer, Ana Inés. 2010. "The Politicization of Private Persona: Exceptional Leaders or the New Rule? The Case of the United Kingdom and the Blair Effect." The International Journal of Press/Politics 15 (1): 60-76.

Lenz, Gabriel, and Chappell Lawson. 2011. "Looking the Part: Television Leads Less Informed Citizens to Vote Based on Candidates' Appearance." American Journal of Political Science 55 (3): 574-89.

Lewis, Carmen C., and Joey F. George. 2008. "Cross-Cultural Deception in Social Networking Sites and Face-to-Face Communication." Computers in Human Behavior 24 (6): 2945-64.

Mair, Peter. 2006. Ruling the Void? The Hollowing of Western Democracy. London: Verso Books.

Mair, Peter, Wolfgang C. Müller, and Fritz Plasser, eds. 2004. Political Parties and Electoral Change. London: Sage.

Mazzoleni, Giampietro. 1987. "Media Logic and Party Logic in Campaign Coverage: The Italian General Election of 1983.” European Journal of Communication 2 (1): 81-103.

Mazzoleni, Giampietro. 2000. "A Return to Civic and Political Engagement Prompted by Personalized Political Leadership?" Political Communication 17 (4): 325-28.

McLeod, Jack, Carroll Glynn, and Daniel McDonald. 1983. "Issues and Images: The Influence of Media Reliance in Voting Decisions." Communication Research 10 (1): 37-58.

Mendelsohn, Matthew. 1996. "The Media and Interpersonal Communications: The Priming of Issues, Leaders, and Party Identification.” Journal of Politics 58 (1): 112-25.

Mughan, Anthony. 2000. Media and the Presidentialization of Parliamentary Elections. Basingstoke: Palgrave Macmillan.

Nai, Alessandro. 2018. "Going Negative, Worldwide: Towards a General Understanding of Determinants and Targets of Negative Campaigning." Government and Opposition 2018:1-26.

Ohr, Dieter. 2011. “Changing Patterns of Political Communication”. In Political Leaders and Democratic Elections, ed. Kees Aarts, André Blais and Hermann Schmitt, 11-34. Oxford: Oxford University Press.

Postman, Neil. 1986. Amusing Ourselves to Death: Public Discourse in the Age of Show Business. New York: Penguin Books.

Prior, Markus. 2006. "The Incumbent in the Living Room: The Rise of Television and the Incumbency Advantage in the U.S. House Elections." The Journal of Politics 68 (3): $657-73$.

Prior, Markus. 2009. "The Immensely Inflated News Audience: Assessing Bias in Self-Reported News Exposure.” Public Opinion Quarterly 73:130-43.

Prior, Markus. 2013. "The Challenge of Measuring Media Exposure: Reply to Dilliplane, Goldman, and Mutz." Political Communication 30 (4): 620-34.

Rahat, Gideon, and Ofir Kenig. 2018. From Party Politics to Personalized Politics? Oxford: Oxford University Press.

Rahat, Gideon, and Tamir Sheafer. 2007. "The Personalization(s) of Politics: Israel, 19492003." Political Communication 24 (1): 65-80.

Rico, Guillem. 2014. "Political Sophistication and Media Consumption as Factors of Personalization.” In Personality Politics? The Role of Leader Evaluations in Democratic 
Elections, ed. Marina Costa Lobo and John Curtice, 127-47. Oxford: Oxford University Press.

Salgado, Susana. 2007. Os Veículos da Mensagem Politica. Estudo de uma campanha eleitoral nos media [The Vehicles of the Political Message. Study of a Media Election Campaign]. Lisbon: Livros Horizonte.

Sartori, Giovanni. 1989. "Video-Power." Government and Opposition 24 (1): 39-53.

Schulz, Winfried, Reimar Zeh, and Oliver Quiring. 2005. "Voters in a Changing Media Environment: A Data-Based Retrospective on Consequences of Media Change in Germany.” European Journal of Communication 20 (1): 55-88.

Sheafer, Tamir. 2001. "Charismatic Skills and Media Legitimacy: An Actor-Centered Approach to Understanding the Political Communication Competition." Communication Research 28 (6): 711-36.

Shehata, Adam, and Jesper Strömback. 2011. "A Matter of Context: A Comparative Study of Media Environments and News Consumption Gaps in Europe." Political Communication 28 (1): 110-34.

Strömback, Jesper. 2008. "Four Phases of Mediatization: An Analysis of the Mediatization of Politics." The International Journal of Press/Politics 13 (3): 228-46.

Strömback, Jesper, Monika Djerf-Pierre, and Adam Shehata. 2013. "The Dynamics of Political Interest and News Media Consumption: A Longitudinal Perspective.” International Journal of Public Opinion Research 4 (1): 414-35.

Strömback, Jesper, and Adam Shehata. 2010. "Media Malaise or a Virtuous Circle? Exploring the Causal Relationships between News Media Exposure, Political News Attention and Political Interest.” European Journal of Political Research 49 (5): 575-97.

Takens, Janet, Jan Kleinnijenhuis, Anita van Hoof, and Wouter van Atteveldt. 2015. "Party Leaders in the Media and Voting Behavior: Priming Rather than Learning or Projections." Political Communication 32 (2): 249-67.

Todorov, Alexander, Anesu Mandisodza, Amir Goren, and Crystal C. Hall. 2005. "Inferences of Competence from Faces Predict Election Outcomes." Science 308 (5728): 1623-26.

van Aelst, Peter. 2007. Toeschouwer, speler of scheidsrechter? Een studie naar de rol van de media in de verkiezingscampagne van 2003 [Spectator, player or referee? A study into the role of the media in the 2003 election campaign]. Bruges, Belgium: Vanden Broele.

van Aelst, Peter, Tamir Sheafer, and James Stanyer. 2011. "The Personalization of Mediated Political Communication: A Review of Concepts, Operationalizations and Key Findings." Journalism 13 (2): 203-20.

Yamamoto, Masahiro, Matthew J. Kushin, and Francis Dalisay. 2015. "Social Media and Mobiles as Political Mobilization Forces for Young Adults: Examining the Moderating Role of Online Political Expression in Political Participation.” New Media \& Society 17 (6): 880-98.

Zhong, Bu, Marie Hardin, and Tao Sun. 2011. "Less Effortful Thinking Leads to More Social Networking? The Associations between the Use of Social Network Sites and Personality Traits." Computers in Human Behavior 27 (3): 1265-71.

\section{Author Biographies}

Diego Garzia is senior researcher and lecturer at the University of Lucerne. His current research project (financed by an "Ambizione" grant from the Swiss National Science Foundation) investigates the extent to which political leaders have come to affect voters' choice as well as the role played by old and new media in driving this development across time. On this topic, he 
published a monograph titled Personalization of Politics and Electoral Change (Palgrave, 2014) and articles in journals such as Electoral Studies, Party Politics, Political Communication, Political Psychology, and West European Politics.

Frederico Ferreira da Silva is a PhD researcher at the European University Institute, Florence. His doctoral thesis focuses on the effects of the personalization of politics on voting behavior in West European democracies. On this topic, he published articles in Electoral Studies, European Journal of Political Research, and West European Politics.

Andrea De Angelis is senior researcher and lecturer at the University of Lucerne. He holds a $\mathrm{PhD}$ in Political and Social Sciences from the European University Institute, Florence. His research interests include comparative political behavior, political communication, and quantitative methods. On these topics, he published articles in Comparative Political Studies, Electoral Studies, and Political Communication. 